\title{
REVIEW
}

\section{Renal oxygenation in clinical acute kidney injury}

\author{
Sven-Erik Ricksten*, Gudrun Bragadottir, Bengt Redfors \\ This article is one of ten reviews selected from the Annual Update in Intensive Care and Emergency Medicine 2013 and co-published as a series \\ in Critical Care. Other articles in the series can be found online at http://ccforum.com/series/annualupdate2013. Further information about the \\ Annual Update in Intensive Care and Emergency Medicine is available from http://www.springer.com/series/8901.
}

\section{Introduction}

Renal oxygenation is defined as the relationship between renal oxygen delivery $\left(\mathrm{DO}_{2}\right)$ and renal oxygen consumption $\left(\mathrm{VO}_{2}\right)$ and it can easily be shown that the inverse of this relationship is equivalent to renal extraction of $\mathrm{O}_{2}$ $\left(\mathrm{O}_{2} \mathrm{Ex}\right)$. An increase in renal $\mathrm{O}_{2} \mathrm{Ex}$ means that renal $\mathrm{DO}_{2}$ has decreased in relation to renal $\mathrm{VO}_{2}$, i. e., renal oxygenation is impaired, and vice versa. When compared to other major organs, renal $\mathrm{VO}_{2}$ is relatively high, second only to the heart. In sedated, mechanically ventilated patients, renal $\mathrm{VO}_{2}$ is two-thirds $(10 \mathrm{ml} / \mathrm{min})$ that of myocardial oxygen consumption $(15 \mathrm{ml} / \mathrm{min}$ ) (Table 1 ) $[1,2]$. Renal blood flow, which accounts for approximately $20 \%$ of cardiac output, is three times higher than myocardial blood flow in this group of patients. Renal $\mathrm{O}_{2} \mathrm{Ex}$ in the non-failing kidney is therefore low, $10 \%$, compared with, e.g., the heart, in which $\mathrm{O}_{2} \mathrm{E}_{\mathrm{X}}$ is $55 \%$ (Table 1).

\section{Determinants of renal oxygenation}

It is well known from experimental studies that tubular sodium reabsorption is the major determinant of renal $\mathrm{VO}_{2}$ [3] and that under normal physiological conditions, approximately $80 \%$ is used to drive active tubular transport of particularly sodium, but also glucose, amino acids and other solutes. Tubular transport processes are highly load-dependent and it has been shown in experimental studies [4] and in patients [2,5-7] that there is a close linear correlation between glomerular filtration rate (GFR), renal sodium reabsorption and renal $\mathrm{VO}_{2}$ (Fig. 1). The filtered load of sodium is, thus, an important determinant of renal $\mathrm{VO}_{2}$ and maneuvers that decrease GFR and the tubular sodium load act to decrease tubular sodium reabsorption and renal $\mathrm{VO}_{2}$, and vice versa [8]. It has been shown that renal $\mathrm{O}_{2} \mathrm{Ex}$ remains stable over a wide range of renal blood flows, which means that

*Correspondence: sven-erik.ricksten@aniv.gu.se

Department of Anesthesiology and Intensive Care Medicine, Sahlgrenska Academy, University of Gothenburg, Sahlgrenska University Hospital, 41345 Gothenburg, Sweden
Table 1. Renal and myocardial oxygen/demand supply relationship in postoperative mechanically ventilated patients

\begin{tabular}{lcc}
\hline & Kidney & Heart \\
\hline Oxygen consumption $(\mathrm{ml} / \mathrm{min})$ & 10 & 15 \\
Blood flow $(\mathrm{ml} / \mathrm{min})$ & 750 & 250 \\
Oxygen extraction $(\%)$ & 10 & 55 \\
\hline
\end{tabular}

changes in renal $\mathrm{DO}_{2}$, caused by changes in renal blood flow, are directly offset by changes in renal $\mathrm{VO}_{2}$ [9], i. e., renal $\mathrm{VO}_{2}$ is flow-dependent. Thus, unlike other organs where increases in blood flow will improve oxygenation, increased renal blood flow augments GFR and the filtered load of sodium, which will increase renal $\mathrm{VO}_{2}$. Due to this flow-dependency of renal $\mathrm{VO}_{2}$, renal oxygenation will remain constant, as long as renal blood flow and GFR change in parallel.

\section{Regional intrarenal oxygenation and medullary hypoxia}

The relatively high renal blood flow is directed preferentially to the cortex to optimize the filtration process and solute reabsorption. In contrast, blood flow in the outer medulla is less than $50 \%$ of the cortical blood flow to preserve osmotic gradients and to enhance urinary concentration [10]. The combination of low medullary perfusion, high oxygen consumption of the medullary thick ascending limbs (mTAL) and the countercurrent exchange of oxygen within the vasa recta, results in a poorly oxygenated outer medulla [11]. Oxygen availability is, therefore, low in the outer medulla, which has an oxygen tissue partial pressure $\left(\mathrm{PO}_{2}\right)$ of $10-20 \mathrm{~mm} \mathrm{Hg}$ compared to $50 \mathrm{~mm} \mathrm{Hg}$ in the cortex. Thus, as the outer medulla is on the border of hypoxia already under normal conditions, it is particularly sensitive to prolonged or intermittent episodes of low renal $\mathrm{DO}_{2}$, caused by hypoperfusion or hemodilution. This condition may occur, in particular, after major surgery (especially cardiac or vascular surgery) or severe heart failure, which are 

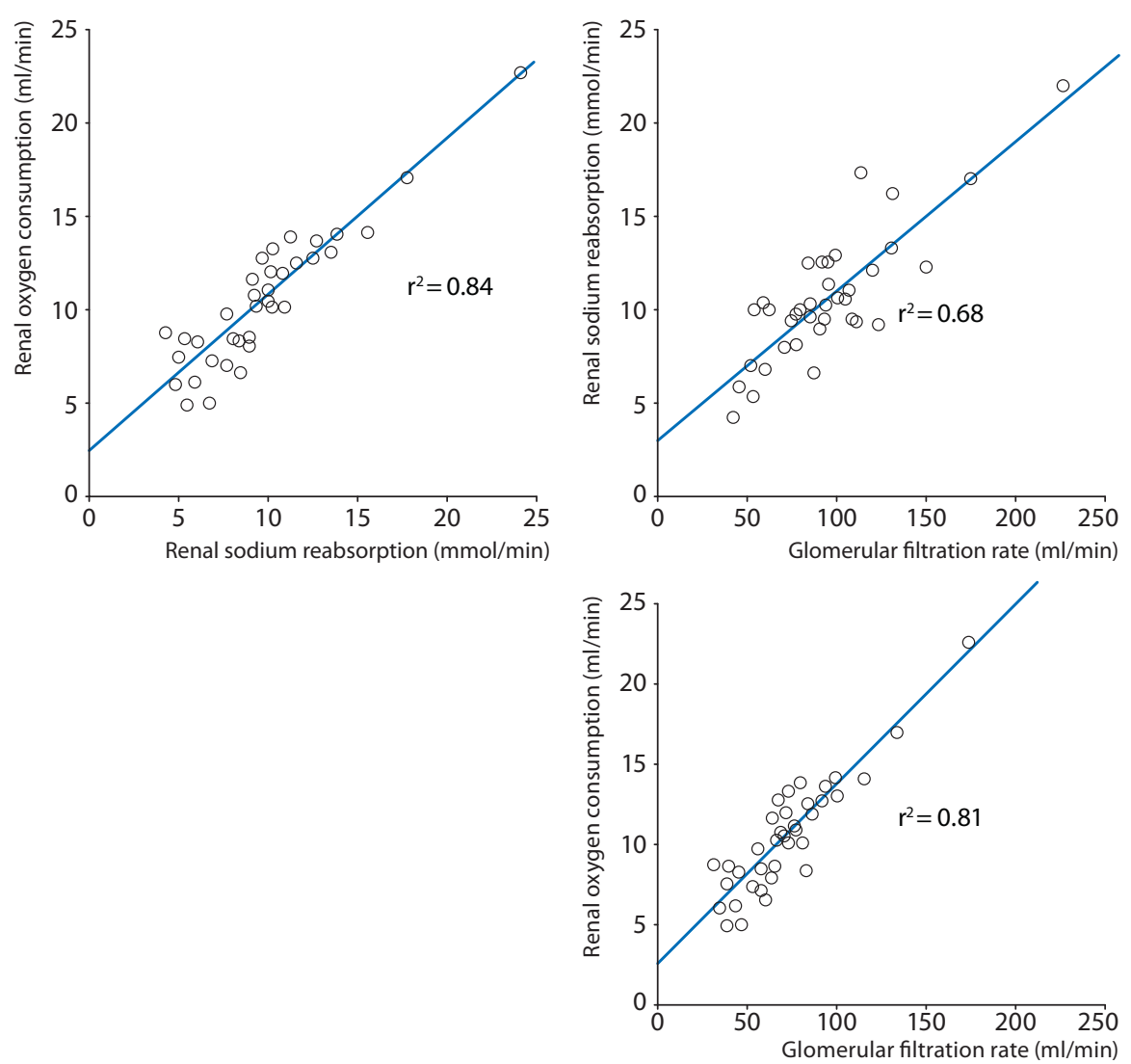

Figure 1. Demonstrates the close relationships between renal sodium reabsorption, renal oxygen consumption and glomerular filtration rate in postoperative patients $(n=37)$ undergoing uncomplicated cardiac surgery. Data from [2].

common causes of ischemic acute kidney injury (AKI) in the intensive care unit (ICU).

Cardiovascular surgery is a 'clinical model' of human AKI. Because it is known when postoperative AKI may occur, in this group of patients, timely, therapeutic interventions for prevention and treatment of early AKI could be instituted. In this situation, it would be logical to improve the renal oxygen supply/demand relationship by augmenting renal $\mathrm{DO}_{2}$ and/or reducing renal $\mathrm{VO}_{2}$, i. e., to improve renal oxygenation.

\section{Effects of diuretics on renal oxygenation in the postoperative patient}

It has repeatedly been shown in experimental studies that furosemide and other loop-diuretics (ethacrynic acid, bumetanide) inhibit renal sodium reabsorption and $\mathrm{VO}_{2}$ in the mTAL (e.g., [12]). This decrease in reabsorptive work will increase oxygen availability and consequently increase the tissue $\mathrm{PO}_{2}$ of the medulla [11]. Because of this decrease in renal oxygen demand, furosemide could potentially exert preventive renoprotective effects. Indeed, several reports have demonstrated that furosemide causes renoprotection in experimental ischemic AKI (e.g., $[13,14])$. Most likely this is mediated by a decrease in medullary $\mathrm{VO}_{2}$ which will increase the tolerance to renal ischemia, but it has also been suggested that the greater urine flow may 'flush out' tubular casts and thereby reduce intratubular obstruction and the backleak of filtered urine [15].

Prasad et al. demonstrated in conscious volunteers that $20 \mathrm{mg}$ of furosemide increased medullary oxygenation, using the blood oxygen level-dependent magnetic resonance imaging technique (BOLD MRI) [16]. In contrast, acetazolamide, which inhibits tubular reabsorption of the proximal tubules in the cortex and which does not affect medullary $\mathrm{PO}_{2}$ in experimental studies, did not affect medullary oxygenation.

Swärd et al. evaluated the renal effects of a bolus dose of furosemide $(0.5 \mathrm{mg} / \mathrm{kg})$ followed by an infusion $(0.5 \mathrm{mg} /$ $\mathrm{kg} / \mathrm{h}$ ) in the early period after cardiac surgery with cardiopulmonary bypass $(\mathrm{CPB})$, using the retrograde renal vein thermodilution technique and renal extraction of ${ }^{51}$ chromium-ethylene-diaminetetraacetic acid $\left({ }^{51} \mathrm{Cr}\right.$-EDTA) for rapid bedside estimation of RBF and GFR without the need for urine collection [5] (Fig. 2). Furosemide increased fractional excretion of sodium (excreted 

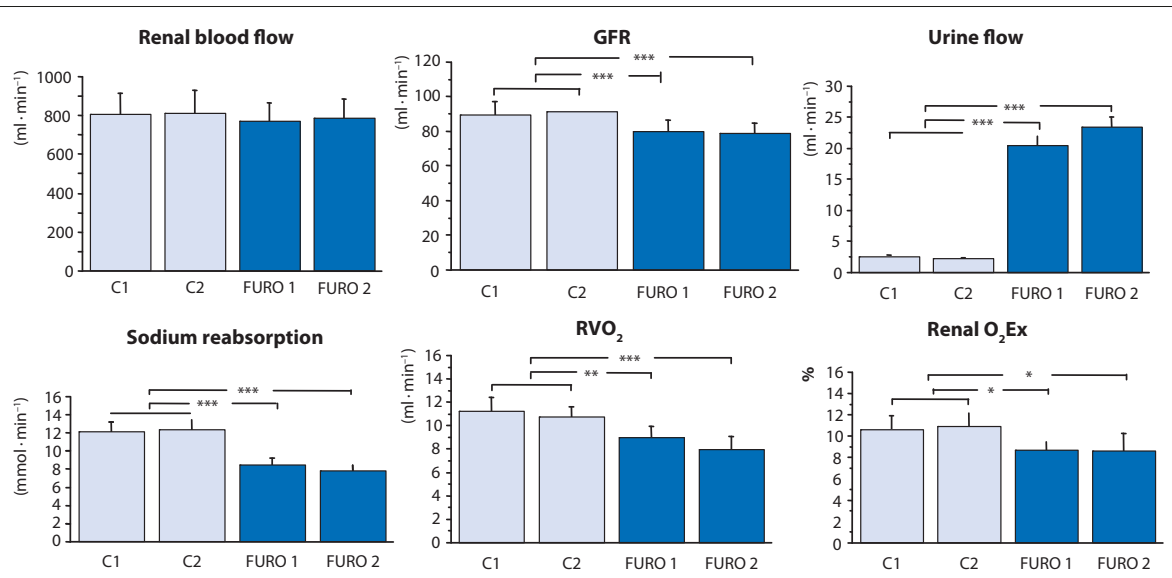

Figure 2. Renal effects of furosemide $0.5 \mathrm{mg} / \mathrm{kg}$ bolus $+0.5 \mathrm{mg} / \mathrm{kg} / \mathrm{h}$ infusion on renal blood flow, glomerular filtration rate (GFR), urine flow, sodium reabsorption, renal oxygen consumption $\left(\mathrm{RVO}_{2}\right)$ and renal oxygen extraction (renal $\mathrm{O}_{2}$ Ex). Furosemide improves renal oxygenation by a decrease in renal sodium reabsorption and $\mathrm{RVO}_{2}$. Data from [5].

sodium/filtered sodium) from $2 \%$ to $25 \%$ and caused a 10 -fold increase in urine flow because of a $28 \%$ decrease in tubular sodium reabsorption. These changes were in turn associated with a $23 \%$ decrease in renal $\mathrm{VO}_{2}$. Thus, furosemide decreased renal $\mathrm{O}_{2} \mathrm{Ex}$ and improved renal oxygenation as renal blood flow was not significantly affected by the diuretic. Interestingly, GFR decreased by $12 \%$ with furosemide, which could be explained by an increased delivery of sodium to the distal tubules activating the tubuloglomerular feedback mechanism, eventually inducing a constriction of the afferent arterioles and a decrease in GFR [17]. This mechanism could explain the findings of Lassnigg et al., who demonstrated in low-risk cardiac surgery patients with normal renal function that furosemide lowered creatinine clearance postoperatively [18]. The authors, therefore, suggested that loop-diuretics could be detrimental to the patients in terms of renal function and outcome. Another hypothesis would be that furosemide improves the renal oxygen demand/supply relationship and, thus, could increase the tolerance to perioperative renal ischemia, and that the mild to moderate fall in GFR with furosemide is a direct pharmacological consequence (tubuloglomerular feedback activation) of the agent which, if anything, would further decrease renal $\mathrm{VO}_{2}$. In future studies, the potential preventive renoprotective effects of furosemide should be evaluated in high-risk surgical patients. Furthermore, GFR or creatinine clearance should not be used as the early primary end-point in such studies, because of the furosemide-induced pharmacological activation of the tubuloglomerular feedback mechanism, which will per se decrease GFR. Instead markers of tubular injury should be measured, to evaluate whether or not the improved renal oxygenation with furosemide could prevent tubular ischemic cell injury in high-risk surgical patients.

\section{Effects of dopaminergic agents on renal oxygenation in the postoperative patient}

Dopamine has been used to prevent acute renal dysfunction in cardiac surgery in the belief that dopamine increases renal blood flow. The preventive effect has, however, been questioned [19-21]. A prospective, randomized controlled trial showed that low-dose dopamine did not affect renal outcome in septic patients with early AKI [22]. It has also been speculated that a dopamine-induced inhibition of proximal tubular $\mathrm{Na}^{+}$ reabsorption may increase delivery of $\mathrm{Na}^{+}$to potentially ischemic distal tubular cells in the medulla, which would increase their oxygen demands [19]. Thus, a dopamine-induced increase in renal $\mathrm{VO}_{2}$ may have the potential to impair renal oxygenation, which could be detrimental in the treatment of early ischemic acute renal failure [19].

Redfors et al. recently studied the effects of low-dose $(2-4 \mu \mathrm{g} / \mathrm{kg} / \mathrm{min})$ dopamine on renal blood flow, GFR, tubular sodium reabsorption, renal $\mathrm{VO}_{2}$ and the renal oxygen demand/supply relationship in post-cardiac surgery patients [23]. Renal blood flow was estimated by two independent techniques, the retrograde renal vein thermodilution technique and the paraminohippuric acid $(\mathrm{PAH})$ infusion clearance technique, with correction for renal extraction of PAH. Interestingly, low-dose dopamine induced pronounced renal vasodilation with a 45-55\% increase in renal blood flow. One would expect that such a marked increase in renal blood flow would be accompanied by a proportional increase in GFR (Fig. 3). However, GFR was not significantly affected by dopamine. Thus, because of the lack of effect of dopamine on GFR, renal $\mathrm{VO}_{2}$ was not affected and, consequently, renal oxygenation was improved (Fig. 3). Thus, the hypothesis put forward by Jones and Bellomo [19], that dopamine may 

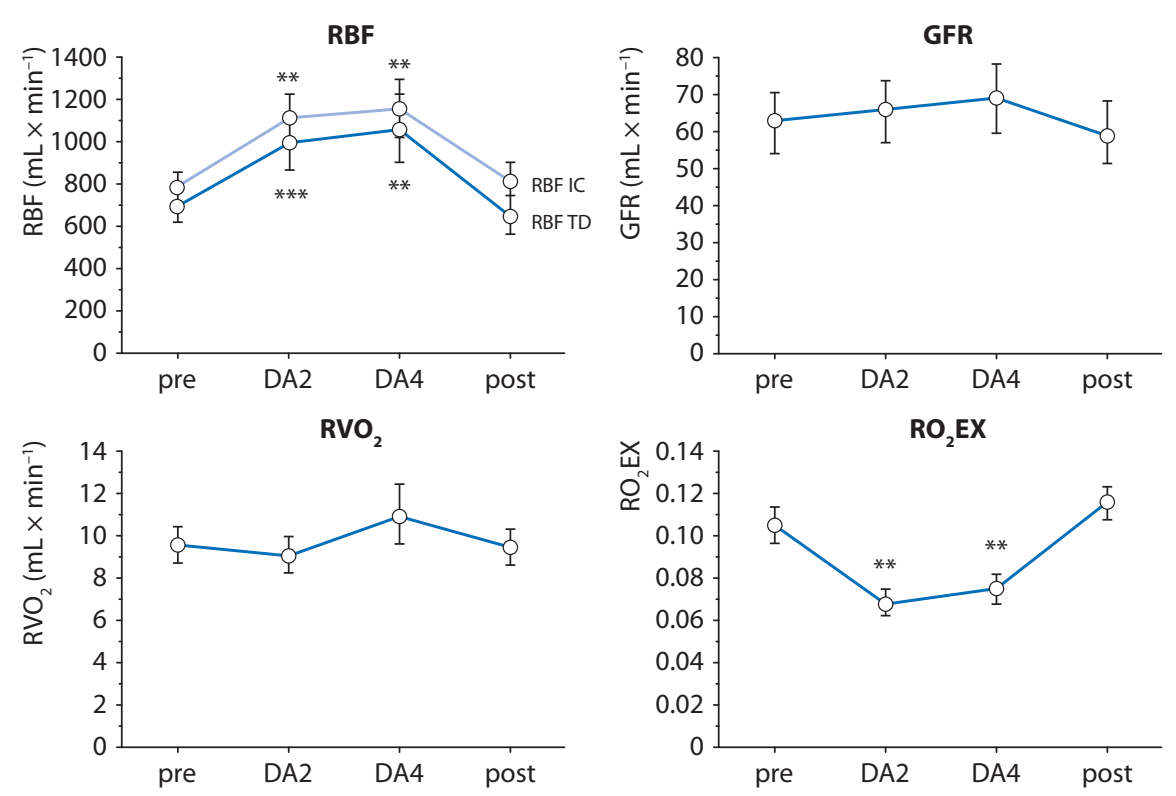

Figure 3. Effects of 2 and $4 \mu \mathrm{g} / \mathrm{kg} / \mathrm{min}$ of dopamine (DA2, DA4) on renal blood flow (RBF), glomerular filtration rate (GFR), renal oxygen consumption $\left(\mathrm{RVO}_{2}\right)$ and renal oxygen extraction $\left(\mathrm{RO}_{2} \mathrm{Ex}\right)$ in postoperative patients. RBF was measured by two independent techniques, retrograde renal vein thermodilution (RBF-TD) and infusion clearance for paraaminohippuric acid (PAH), with correction for renal extraction of PAH (RBF-IC). Note that low-dose dopamine improved renal oxygenation by a profound renal vasodilation with no changes in $\mathrm{GFR}$ or RVO. From [23] with permission.

impair renal oxygenation is not supported by the data from Redfors et al. [23].

The lack of effect of dopamine on GFR in postoperative patients highlights the common misunderstanding that an increase in renal blood flow by a renal vasodilator is always accompanied by an increase in GFR. The effect of a renal vasodilator on GFR is dependent on its effect on the longitudinal distribution of renal vascular resistance. The dopamine-induced increase in renal blood flow with no significant effect on GFR is explained by a renal vasodilatory action on pre- and postglomerular resistance vessels. Experimental studies have revealed that dopamine-mediated renal vasodilation predominantly is effected at the post-synaptic dopamine-1 (DA-1) receptors and that dopamine and other DA-1-receptor agonists dilate afferent and efferent arterioles to the same degree [24]. Studies on the effects of low-dose dopamine in volunteers or patients on renal plasma flow and GFR, as measured by clearance techniques are listed in Table 2 . Note that in all studies, renal plasma flow increased, whereas in half the studies, GFR was not affected; in the remaining half, the increase in GFR was considerably lower than the increase in renal plasma flow.

The capacity of dopamine to improve renal oxygenation in postoperative patients would make it suitable for prevention of $\mathrm{AKI}$, as it would increase the tolerance to renal ischemia in major surgery. However, the potential preventive effect of dopamine has not been evaluated in high-risk cardiovascular surgery. Although interest in the use of dopamine for renoprotection has decreased, interest in the use of another dopaminergic agent, fenoldopam, which exerts the same renal effects as dopamine [24], is, strangely enough, increasing. Fenoldopam is a selective dopamine- 1 receptor agonist with no $\beta-1$ or $\alpha$-adrenergic receptor agonistic effects and similar to dopamine, it increases renal plasma flow with no effects on GFR, as demonstrated in healthy volunteers [25]. In three preventive, randomized controlled trials in abdominal aortic surgery [26] and high-risk cardiac surgery [27], fenoldopam improved creatinine clearance compared to placebo. These beneficial effects on renal outcome with fenoldopam and the lack of similar beneficial effects with dopamine (see above), despite similar pharmacological actions, could be explained by the fact that the potential preventive renal effects with dopamine and fenoldopam were evaluated in low-risk and high-risk patients, respectively. Bove et al. compared the preventive effects of fenoldopam and dopamine $(2.5 \mu \mathrm{g} / \mathrm{kg} / \mathrm{min})$ on renal excretory function in high-risk cardiac surgery and found, not surprisingly, no difference between the two dopaminergic agents on percentage postoperative increase in serum creatinine [28].

\section{Renal oxygenation in clinical ischemic acute kidney injury}

Patients undergoing cardiac surgery with $\mathrm{CPB}$ are at high risk of developing postoperative AKI, with a reported 


\begin{tabular}{|c|c|c|c|c|}
\hline Author [ref] & Year & Patients & RPF & GFR \\
\hline Ter Wee [51] & 1986 & Volunteers & Increase & Increase \\
\hline Schoors [52] & 1990 & Volunteers & Increase & No effect \\
\hline Olsen [53] & 1993 & Volunteers & Increase & No effect \\
\hline Olsen [54] & 1993 & Volunteers & Increase & Increase \\
\hline Olsen [55] & 1994 & Volunteers & Increase & No effect \\
\hline Richer [56] & 1996 & Volunteers & Increase & No effect \\
\hline McDonald [57] & 1964 & Heart failure & Increase & Increase \\
\hline Rosenblum [58] & 1972 & Heart failure & Increase & Increase \\
\hline Schwartz [59] & 1988 & Vascular surgery & Increase & Increase \\
\hline Graves [60] & 1993 & Burn injury & Increase & No effect \\
\hline Ungar [61] & 2004 & Heart failure & Increase & Increase \\
\hline Redfors [23] & 2010 & Cardiac surgery & Increase & No effect \\
\hline
\end{tabular}

incidence of $15-30 \%$, causing significant morbidity and mortality $[29,30]$. In patients undergoing major cardiovascular surgery, even minor changes in serum creatinine are associated with increased in-patient mortality [31]. Postoperative AKI in this group of patients is considered a consequence of impaired renal $\mathrm{DO}_{2}$, in turn caused by intra-operative hypotension and hemodilution-induced anemia [32], as well as perioperative low cardiac output [29].

It has provocatively been stated that "acute renal failure is acute renal success" [33,34], as a reduction in GFR in AKI should lead to a reduction in the renal reabsorptive workload, thus preserving medullary oxygenation with a reduced risk of further aggravation of ischemia. In patients with $\mathrm{AKI}$, there are few data on renal $\mathrm{VO}_{2}$, renal blood flow, GFR and renal oxygenation and current views on renal oxygenation are presumptive and largely based on experimental studies.

Redfors et al. recently studied renal perfusion, filtration and oxygenation in patients with preoperative normal renal function developing early AKI (50-200 \% increase in serum creatinine) after complicated cardiac surgery [2]. Renal blood flow was measured by renal vein retrograde thermodilution and by infusion clearance of PAH corrected for renal extraction of PAH. In spite of a normalization of cardiac index $(\mathrm{CI})$ with inotropic treatment with or without intra-aortic balloon pump (IABP), renal oxygenation was severely impaired in patients with early AKI, as demonstrated by a $70 \%$ relative increase in renal $\mathrm{O}_{2} \mathrm{Ex}$, compared to uncomplicated post-cardiac surgery patients with normal renal function This was, in turn, caused by a pronounced renal vasoconstriction and a $40 \%$ lower renal blood flow, in combination with a renal
Table 3. Renal perfusion, filtration and oxygenation in postoperative acute kidney injury (AKI) [2]

\begin{tabular}{lccc}
\hline & $\begin{array}{c}\text { Control group } \\
(\mathbf{n}=\mathbf{3 7})\end{array}$ & $\begin{array}{c}\text { AKI group } \\
(\mathbf{n}=\mathbf{1 2})\end{array}$ & $\begin{array}{c}\mathbf{p} \text { - } \\
\text { value }\end{array}$ \\
\hline Mean arterial pressure $(\mathrm{mm} \mathrm{Hg})$ & $73.9 \pm 1.1$ & $73.5 \pm 0.7$ & $\mathrm{~ns}$ \\
Cardiac index $\left(\mathrm{I} / \mathrm{min} / \mathrm{m}^{2}\right)$ & $2.63 \pm 0.08$ & $2.77 \pm 0.16$ & $\mathrm{~ns}$ \\
$\mathrm{RBF}(\mathrm{ml} / \mathrm{min})$ & $758 \pm 40$ & $477 \pm 54$ & $<0.001$ \\
$\mathrm{RVR}(\mathrm{mm} \mathrm{Hg} / \mathrm{ml} / \mathrm{min})$ & $0.097 \pm 0.005$ & $0.146 \pm 0.015$ & $<0.01$ \\
GFR $(\mathrm{ml} / \mathrm{min})$ & $74.7 \pm 4.7$ & $32.3 \pm 3.6$ & $<0.001$ \\
Sodium reabsorption $(\mathrm{mmol} / \mathrm{min})$ & $9.7 \pm 0.7$ & $4.0 \pm 0.4$ & $<0.001$ \\
Renal oxygen consumption & $10.4 \pm 0.6$ & $11.0 \pm 1.1$ & $\mathrm{~ns}$ \\
(ml/min) & & & \\
Renal oxygen extraction & $0.097 \pm 0.004$ & $0.163 \pm 0.009$ & $<0.001$ \\
\hline
\end{tabular}

RBF: renal blood flow assessed by the thermodilution technique; RVR: renal vascular resistance; GFR: glomerular filtration rate. Values are means \pm SEM.

$\mathrm{VO}_{2}$ that was not significantly different from the control group, despite the $60 \%$ decrease in GFR and renal tubular sodium reabsorption (Table 3). Thus, the renal $\mathrm{VO}_{2}$ of the AKI patients was $1.9 \mathrm{ml} / \mathrm{mmol}$ reabsorbed sodium, a value that was 2.4 times higher than in the uncomplicated control group $(0.82 \mathrm{ml} / \mathrm{mmol}$ reabsorbed sodium). Figure 4 shows the close correlation between GFR and renal $\mathrm{VO}_{2}$ in patients with early AKI after cardiac surgery versus those undergoing uncomplicated surgery with no renal impairment. According to the "acute renal success"hypothesis [42-44], as put forward by several researchers, AKI patients should operate on the lower part of the regression line of the control patients. However, the regression line of the AKI patients is clearly shifted to the left, i. e., at a certain GFR, renal $\mathrm{VO}_{2}$ is higher, speaking against this hypothesis. On the contrary, the $40 \%$ decrease in renal $\mathrm{DO}_{2}$ in combination with a tubular sodium reabsorption at a high oxygen demand, suggests that renal hypoxia is present after the initiation phase of ischemic AKI.

One can only speculate on the mechanisms underlying the leftward shift of the GFR/renal $\mathrm{VO}_{2}$ relationship in AKI patients. A potential explanation could be loss of epithelial cell-polarization and tight junction integrity in AKI, as has been shown in experimental studies and after human renal transplantation [35], making tubular sodium reabsorption less efficient [36]. Another explanation may be diminished renal nitric oxide $(\mathrm{NO})$ generation because of endothelial damage and downregulation of endothelial $\mathrm{NO}$ synthase (eNOS/NOS-3). NO is a major regulator of microvascular oxygen supply and renal $\mathrm{VO}_{2}$ [37]. Through vasodilation, NO increases renal blood flow and hence $\mathrm{DO}_{2}$. Furthermore, contemporary work suggests that $\mathrm{NO}$ acts as a 'brake' on oxidative metabolism at various sites, including direct competition of $\mathrm{NO}$ with oxygen for mitochondrial respiration and inhibition of cytochrome c oxidase [38]. 


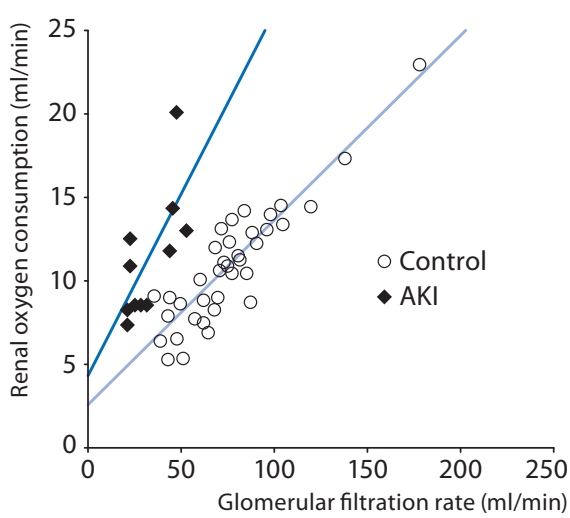

Figure 4. Close correlation between glomerular filtration rate and renal oxygen consumption in uncomplicated postcardiac surgery patients (controls, $\mathrm{n}=37$ ) and in patients with postoperative acute kidney injury (AKI). Note that the slope of the regression line is steeper in the AKI group. Thus filtration and reabsorbtion of sodium consumes approximately 2.5 times more oxygen in the AKI group. From [2] with permission.

\section{Treatment of clinical ischemic AKI}

The major goal in the management of early AKI is to increase GFR. However, because of the close association between GFR, tubular sodium reabsorption and renal $\mathrm{VO}_{2}$ in humans [5-7], a pharmacologically-induced increase in GFR will increase renal $\mathrm{VO}_{2}$ and potentially further impair renal oxygenation in patients with AKI. Thus, an ideal agent to treat ischemic AKI would be one that increases both renal blood flow and GFR, i. e., an agent that preferentially induces vasodilation of the preglomerular resistance vessels. Such an agent will not only increase GFR but also meet the increased renal metabolic demand of the medulla by an increase in renal $\mathrm{DO}_{2}$. It is not likely that the potent renal vasodilator, dopamine, will improve GFR in early clinical ischemic AKI as it exerts a non-specific renal vasodilation of preand postglomerular resistance vessels with a pronounced effect on total renal vascular resistance and renal blood flow but with no or minor effects on glomerular hydraulic pressure and GFR (see above). This could explain why low-dose dopamine $(2 \mu \mathrm{g} / \mathrm{kg} / \mathrm{min})$ does not improve renal outcome, measured as peak serum creatinine, in ICU patients with systemic inflammatory response syndrome and early AKI [22].

Atrial natriuretic peptide (ANP) is a renal vasodilator, which causes a balanced 30-40\% increase in both renal blood flow and GFR in patients with early ischemic AKI after complicated cardiac surgery [39]. Although, the effects of ANP on renal oxygenation have not been studied, it is less likely that ANP would impair renal oxygenation because of its preferential action on the preglomerular resistance vessels. This is further supported by the findings from a prospective, randomized, blinded trial by

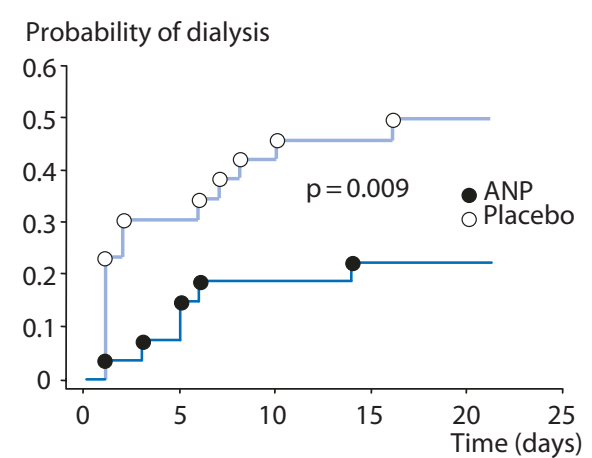

Figure 5. Effects of atrial natriuretic peptide (ANP) vs placebo on probability of dialysis in post-cardiac surgery patients with early acute kidney injury. Modified from [40] with permission.

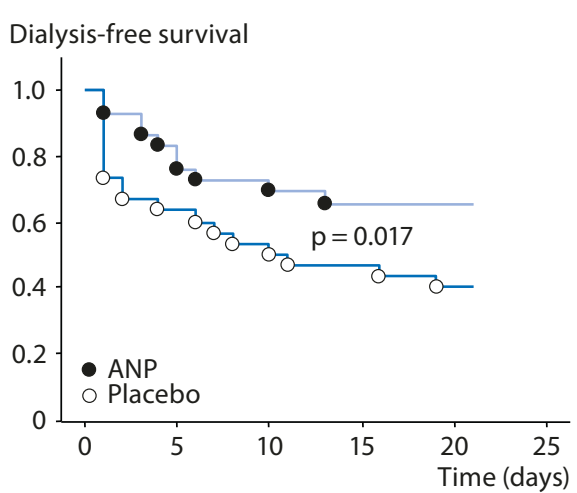

Figure 6. Effects of atrial natriuretic peptide (ANP) vs placebo on dialysis-free survival in post-cardiac surgery patients with early acute kidney injury. Modified from [40] with permission.

Swärd et al., who showed that infusion of ANP enhanced renal excretory function, decreased the probability of dialysis and improved dialysis-free survival in early, ischemic AKI after complicated cardiac surgery [40] (Figs. 5 and 6).

Another approach for the treatment of clinical ischemic AKI would be to target the vascular endothelium and tubular epithelium. Experimental studies have shown that mannitol may decrease ischemia-induced swelling of tubular cells, which might obstruct the tubular lumen [41]. Mannitol treatment has been shown to increase GFR in patients after severe trauma or surgery [42]. In addition, our group has shown that mannitol increases GFR in postoperative cardiac surgery patients possibly by a de-swelling effect on tubular cells [6]. Furthermore, it has been suggested that outer medullary hypoxia may cause endothelial ischemic injury and endothelial cell swelling contributing to congestion and impaired perfusion of this region [43], which could, at least to some extent, explain the high renal vascular resistance seen in clinical early AKI [2]. The effects of mannitol treatment 


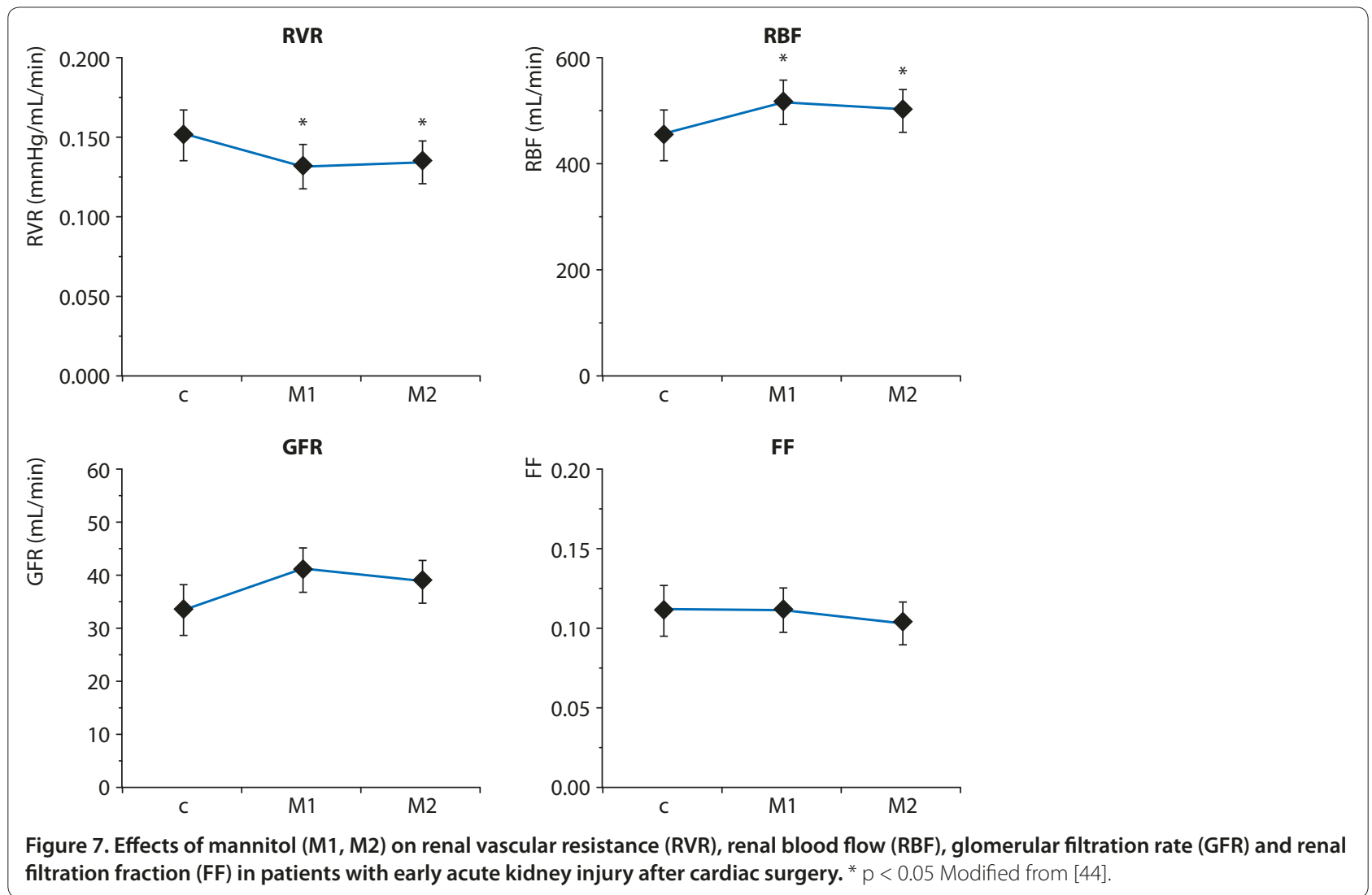

on renal perfusion, filtration and oxygenation were recently studied in patients with normal preoperative creatinine, who developed early AKI after complicated cardiac surgery, requiring inotropic support with or without IABP [44]. Mannitol induced a $60 \%$ increase in diuresis, which was accompanied by decrease in renal vascular resistance and a $12-15 \%$ increase in renal blood flow, while no effects were seen on cardiac index or cardiac filling pressures. Mannitol did not affect filtration fraction or renal oxygenation, suggestive of balanced increases in perfusion/filtration and renal oxygen demand/ supply (Fig. 7).

Vasodilatory shock and AKI: role of norepinephrine Vasodilatory shock is not uncommon after complicated cardiac surgery with $\mathrm{CPB}$ and occurs often in conjunction with postoperative heart failure [45]. The recommended agent for treatment of volume-resuscitated vasodilatory shock is norepinephrine [46]. Patients with vasodilatory shock after cardiac surgery with $\mathrm{CPB}$ may suffer from concomitant AKI. The use of norepinephrine for treatment of vasodilatory shock in patients with ischemic AKI with impaired renal oxygenation is a "two-edged sword" as it may further aggravate renal ischemia. On the other hand, too low a dose of norepinephrine may result in an arterial blood pressure that may be below the limit of renal autoregulation, i. e., when renal blood flow becomes pressure-dependent.

In a recent study in post-cardiac surgery patients with norpinephrine-dependent vasoplegia and concomitant AKI, the effects of norepinephrine on renal perfusion, filtration and oxygenation were evaluated [47]. Norepinephrine infusion rate was randomly and sequentially titrated to target a mean arterial pressures (MAP) of 60, 75 and $90 \mathrm{~mm} \mathrm{Hg}$. At each target MAP, data on renal blood flow, GFR and renal $\mathrm{O}_{2}$ Ex were obtained by the renal vein thermodilution technique and by renal extraction of ${ }^{51} \mathrm{Cr}$-EDTA. At a target MAP of $75 \mathrm{~mm} \mathrm{Hg}$, renal $\mathrm{DO}_{2}(13 \%)$, GFR (27\%) and urine flow were higher and renal $\mathrm{O}_{2} \mathrm{Ex}$ was lower $(-7.4 \%)$ compared with a target MAP of $60 \mathrm{~mm} \mathrm{Hg}$. However, the renal variables did not differ when compared at target MAPs of 75 and $90 \mathrm{~mm} \mathrm{Hg}$ (Fig. 8). Thus, restoration of MAP from 60 to $75 \mathrm{~mm} \mathrm{Hg}$ improves renal $\mathrm{DO}_{2}$, GFR and renal oxygenation in patients with vasodilatory shock and AKI. The pressure-dependent renal perfusion, filtration and oxygenation at levels of MAP below $75 \mathrm{~mm} \mathrm{Hg}$ reflect a more or less exhausted renal autoregulatory reserve.

\section{Low-dose vasopressin and renal oxygenation}

Resistance to norepinephrine and other catecholamines may develop in vasodilatory shock because of adrenergic 

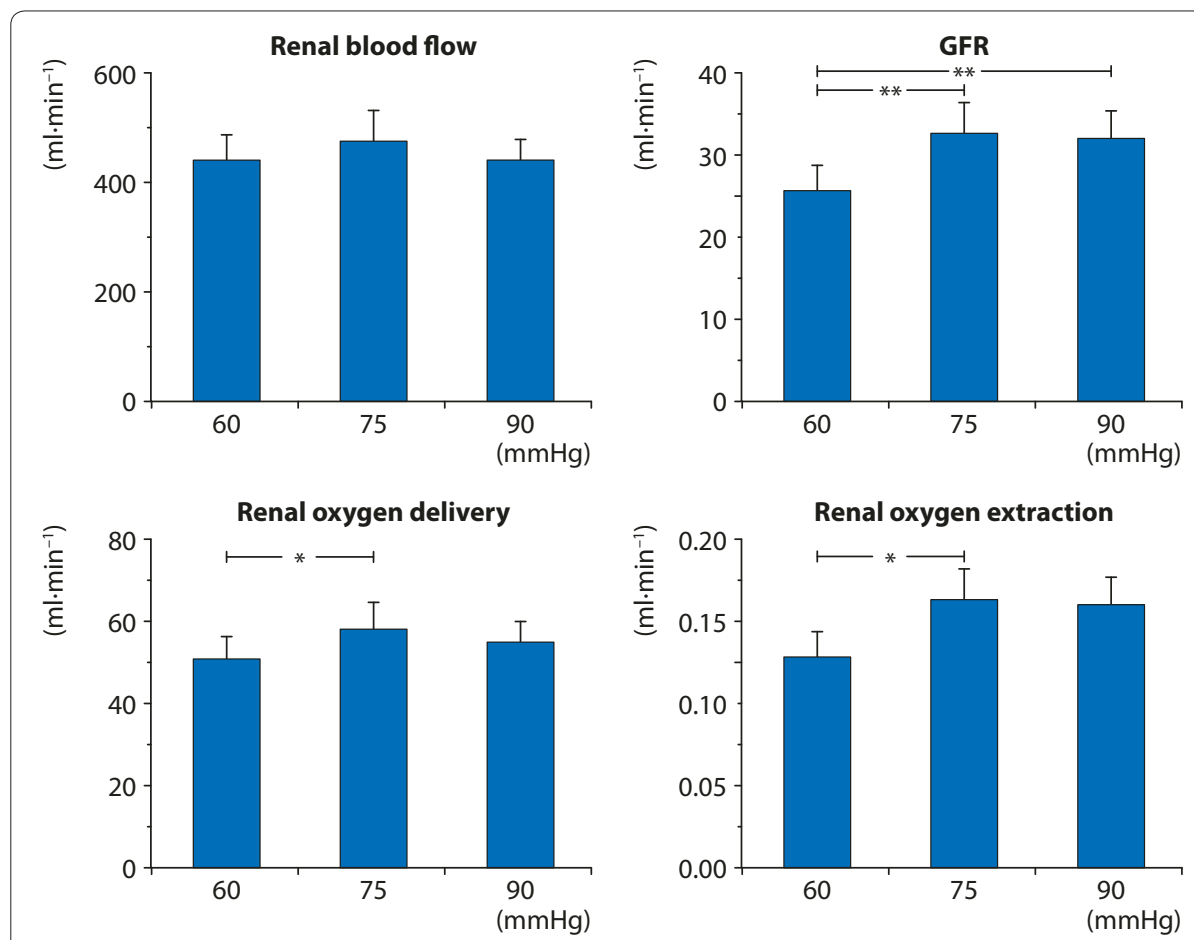

Figure 8. Renal effects of norepinephrine (NE)-induced variations in target mean arterial pressures (MAP) in post-cardiac surgery patients with NE-dependent vasodilatory shock and acute kidney injury. Restoration of MAP from 60 to $75 \mathrm{~mm} \mathrm{Hg}$ improves renal oxygen delivery, GFR and the renal oxygen supply/demand relationship. This pressure-dependent renal perfusion, filtration and oxygenation at levels of MAP below $75 \mathrm{~mm}$ Hg reflect a more or less exhausted renal autoregulatory reserve. Data from [47].

receptor downregulation and endogenous vasodilators. Furthermore, plasma levels of vasopressin are low in post-cardiotomy vasodilatory shock and in septic shock in contrast to hypovolemic and cardiogenic shock [48]. Vasopressin has, therefore, been suggested as an additional or an alternative therapy in catecholaminedependent vasodilatory shock [49]. It has also been reported that vasopressin increases creatinine clearance, a surrogate variable of GFR, in these patients [50]. A more detailed analysis on the effects of low-dose vasopressin on renal oxygenation is lacking.

Bragadottir et al. evaluated the renal effects of lowdoses $(1.2,2.4,4.8 \mathrm{U} / \mathrm{h})$ of vasopressin in post-cardiac surgery patients, doses that did not affect systemic blood pressure [7]. Vasopressin exerted a dose-dependent increase in GFR, sodium reabsorption, renal $\mathrm{VO}_{2}$, renal $\mathrm{O}_{2}$ Ex and renal vascular resistance, whereas renal blood flow decreased. Thus, vasopressin considerably impaired renal oxygenation by postglomerular vasoconstriction, which induced a decrease in renal blood flow and an increase in both GFR and renal $\mathrm{VO}_{2}$ (Fig. 9). From a renal point of view, vasopressin should be used with caution in the treatment of vasodilatory shock, because it has the potential to cause considerable renal oxygen supply/demand mismatch.

\section{Conclusion}

In spite of the apparent luxury oxygenation of the kidneys, with a high renal $\mathrm{DO}_{2}$ in relation to renal $\mathrm{VO}_{2}$, the outer medulla is on the border of hypoxia in the normal situation. Outer medullary hypoxia, caused by low medullary perfusion, high $\mathrm{VO}_{2}$ of the medullary thick ascending limbs and the countercurrent exchange of oxygen, is the price the kidneys have to pay for the urine concentration mechanism. The outer medulla is, therefore, particularly sensitive to prolonged or intermittent episodes of low renal $\mathrm{DO}_{2}$. Dopaminergic agents (dopamine/ fenoldopam) and loop-diuretics improve renal oxygenation, and potentially prevent ischemic AKI, whereas vasopressin impairs renal oxygenation in postoperative patients.

Renal oxygenation is impaired in early clinical ischemic AKI because of a low renal blood flow, caused by vasoconstriction and endothelial swelling, in combination with a tubular reabsorption at a high oxygen demand. ANP is ideally suited for treatment of ischemic $\mathrm{AKI}$, as it preferentially dilates the preglomerular resistance vessels; this will increase GFR but also renal blood flow, meeting the increased oxygen demand of the medulla by an increase in renal $\mathrm{DO}_{2}$. Mannitol increases renal blood flow and GFR in clinical ischemic AKI most likely by endothelial and epithelial de-swelling effects. 


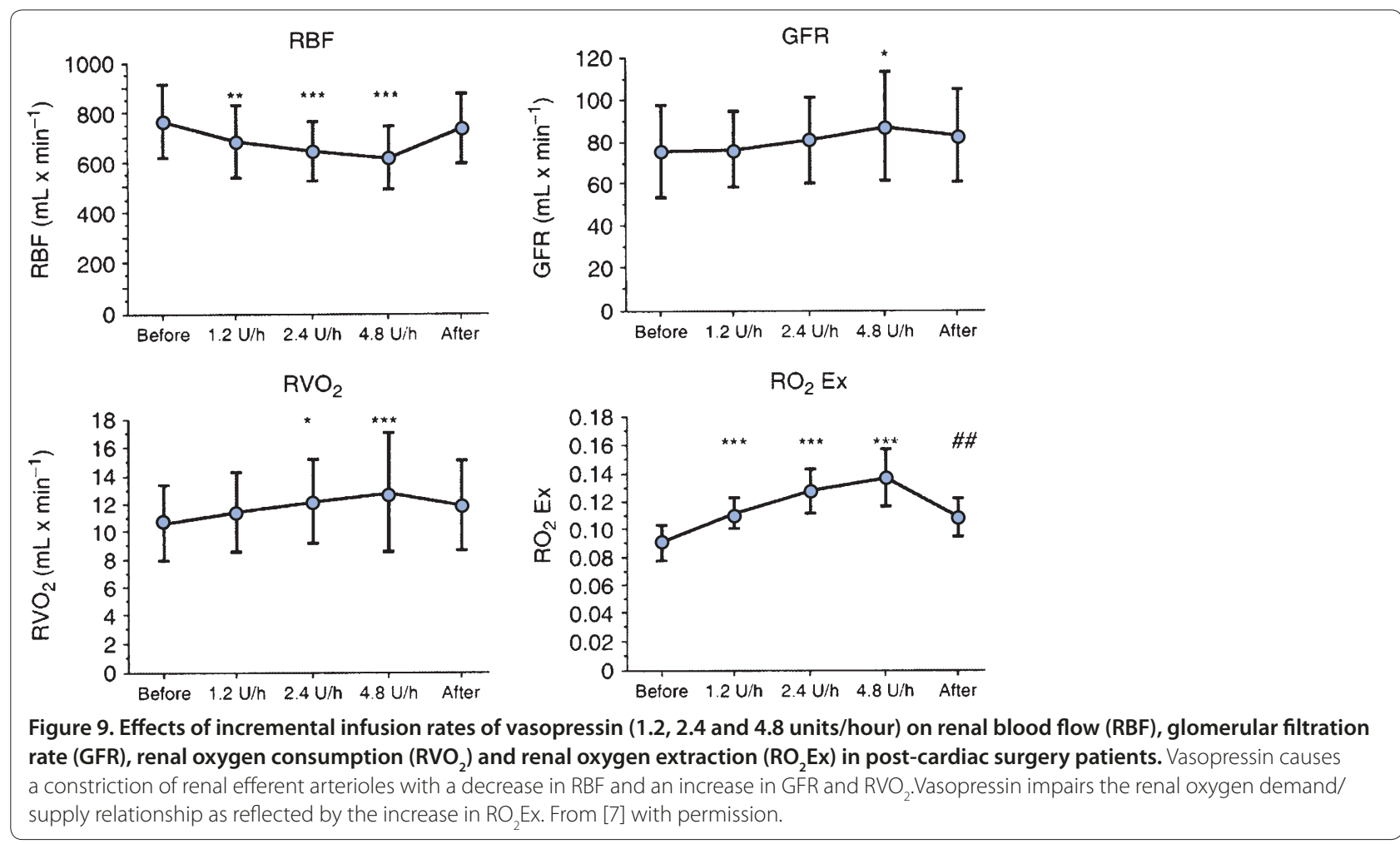

Competing interests

The authors declare that they have no competing interests.

\section{List of abbreviations used}

AKI: acute kidney injury; ANP: atrial natriuretuc peptide; BOLD MRI: bold oxygen level-dependent magnetic resonance imaging; $\mathrm{Cl}$ : cardiac index; CPB cardiopulmonary bypass; Cr-EDTA: chromium-ethylene-diaminetetraacetic acid; DA-1: dopamine-1; $\mathrm{DO}_{2}$ : oxygen delivery; GFR: glomerular filtration rate; IABP: intra-aortic balloon pump; ICU: intensive care unit; MAP: mean arterial pressure; mTAL: medullary thick ascending limbs; NO: nitric oxide; $\mathrm{O}_{2}$ Ex: renal extraction of $\mathrm{O}_{2}$ PAH: paraaminohippuric acid; $\mathrm{PO}_{2}$ : oxygen tissue partial pressure; RBF: renal blood flow; RVR: renal vascular resistance; $\mathrm{VO}_{2}$; renal oxygen consumption.

Published: 19 March 2013

\section{References}

1. Zäll S, Milocco I, Ricksten SE: Effects of adenosine on myocardial blood flow and metabolism after coronary artery bypass surgery. Anesth Analg 1991, 73:689-695.

2. Redfors B, Bragadottir G, Sellgren J, Swärd K, Ricksten SE: Acute renal failure is NOT an "acute renal success" - a clinical study on the renal oxygen supply/demand relationship in acute kidney injury. Crit Care Med 2010, 38:1695-1701.

3. Kiil F, Aukland K, Refsum HE: Renal sodium transport and oxygen consumption. Am J Physiol 1961, 201:511-516.

4. Torelli G, Milla E, Faelli A, Costantini S: Energy requirement for sodium reabsorption in the in vivo rabbit kidney. Am J Physiol 1966, 211:576-580.

5. Swärd K, Valsson F, Sellgren J, Ricksten SE: Differential effects of human atrial natriuretic peptide and furosemide on glomerular filtration rate and renal oxygen consumption in humans. Intensive Care Med 2004, 31:79-85.

6. Redfors B, Swärd K, Sellgren J, Ricksten SE: Effects of mannitol alone and mannitol plus furosemide on renal oxygen consumption, blood flow and glomerular filtration after cardiac surgery. Intensive Care Med 2009, 35:115-122

7. Bragadottir G, Redfors B, Nygren A, Sellgren J, Ricksten SE: Low-dose vasopressin increases glomerular filtration rate, but impairs renal oxygenation in post-cardiac surgery patients. Acta Anaesthesio/ Scand 2009. 53:1052-1059

8. O'Connor PM: Renal oxygen delivery: matching delivery to metabolic demand. Clin Exp Pharmacol Physiol 2006, 33:961-967.

9. Levy MN: Effect of variations of blood flow on renal oxygen extraction. Am JPhysio/ 1960, 199:13-18.

10. Chou SY, Porush JG, Faubert PF: Renal medullary circulation: hormonal control. Kidney Int 1990, 37:1-13.

11. Brezis M, Rosen S: Hypoxia of the renal medulla - its implications for disease. N Engl J Med 1995, 332:647-655.

12. Aukland K, Johannesen J, Kiil F: In vivo measurements of local metabolic rate in the dog kidney. Effect of mersalyl, chlorothiazide, ethacrynic acid and furosemide. Scand J Clin Lab Invest 1969, 23:317-330.

13. Kramer HJ, Schuurmann J, Wassermann C, Dusing R: Prostaglandinindependent protection by furosemide from oliguric ischaemic renal failure in conscious rats. Kidney Int 1980, 17:455-464.

14. Bayati A, Nygren K, Kallskog O, Wolgast M: The effect of loop diuretics on the long-term outcome of post-ischaemic acute renal failure in the rat. Acta Physiol Scand 1990, 139:271-279.

15. Shilliday I, Allison ME: Diuretics in acute renal failure. Ren Fail 1994, 16:3-17.

16. Prasad PV, Edelman RR, Epstein FH: Noninvasive evaluation of intrarenal oxygenation with BOLD MRI. Circulation 1996, 94:3271-3275.

17. Cupples WA, Braam B: Assessment of renal autoregulation. Am J Physiol Renal Physiol 2007, 292:F1105-F11223.

18. Lassnigg A, Donner E, Grubhofer G, Presterl E, Druml W, Hiesmayr M: Lack of renoprotective effects of dopamine and furosemide during cardiac surgery. J Am Soc Nephrol 2000, 11:97-104.

19. Jones $D$, Bellomo R: Renal-dose dopamine: from hypothesis to paradigm to dogma to myth and, finally, superstition? J Intensive Care Med 2005, 20:199-211.

20. Marik PE: Low-dose dopamine: a systematic review. Intensive Care Med 2002, 28:877-883.

21. Woo EB, Tang AT, el-Gamel A, Green halgh D, Patrick M, Jones MT, Hooper TL: Dopamine therapy for patients at risk of renal dysfunction following cardiac surgery: science or fiction? Eur J Cardiothorac Surg 2002, 22:106-111.

22. Bellomo R, Chapman M, Finfer S, Hickling K, Myburgh J: Low-dose dopamine in patients with early renal dysfunction: a placebo-controlled randomised 
trial. Australian and New Zealand Intensive Care Society (ANZICS) Clinical Trials Group. Lancet 2000, 356:2139-2143.

23. Redfors B, Bragadottir G, Sellgren J, Swärd K, Ricksten SE: Dopamine increases renal oxygenation: a clinical study in post-cardiac surgery patients. Acta Anaesthesiol Scand 2010, 54:183-190.

24. Edwards RM: Comparison of the effects of fenoldopam, SK \& F R-87516 and dopamine on renal arterioles in vitro. Eur J Pharmacol 1986, 126:167-170.

25. Mathur VS, Swan SK, Anjum S, Lambrecht LJ , Anjum S, Fellmann J, McGuire D, Epsein M, Luther RR: The effects of fenoldopam, a selective dopamine receptor agonist, on systemic and renal hemodynamics in normotensive subjects. Crit Care Med 1999, 27:1832-1837.

26. Halpenny M, Rushe C, Breen P, Cunningham AJ, Boucher-Hayes D, Shorten GD: The effects of fenoldopam on renal function in patients undergoing elective aortic surgery. Eur J Anaesthesiol 2002, 19:32-39.

27. Cogliati AA, Vellutini R, Nardini A, Urovi S, Hamdan M, Landoni G, Guelfi P: Fenoldopam infusion for renal protection in high-risk cardiac surgery patients: a randomized clinical study. J Cardiothorac Vasc Anesth 2007, 21:847-850.

28. Bove T, Landoni G, Calabrò MG, Aletti G, Marino G, Cerchierini E, Crescenzi G, Zangrillo A: Renoprotective action of fenoldopam in high-risk patients undergoing cardiac surgery: a prospective, double-blind, randomized clinical trial. Circulation 2005, 111:3230-3235.

29. Mangano CM, Diamondstone LS, Ramsay JG, Aggarwal A, Herskowitz A, Mangano DT: Renal dysfunction after myocardial revascularization: risk factors, adverse outcomes, and hospital resource utilization. The Multicenter Study of Perioperative Ischemia Research Group. Ann Intern Med 1998, 128:194-203.

30. Englberger L, Suri RM, Li Z, Casey ET, Daily RC, Dearani HA, Schaff HV: Clinical accuracy of RIFLE and Acute Kidney Injury Network (AKIN) criteria for acute kidney injury in patients undergoing cardiac surgery. Crit Care 2011, 15:R16.

31. Lassnigg A, Schmidlin D, Mouhieddine M, Bachmann LM, Druml W, Bauer P, Hiesmayr M: Minimal changes of serum creatinine predict prognosis in patients after cardiothoracic surgery: a prospective cohort study. J Am Soc Nephrol 2004, 15:1597-1605.

32. Kanji HD, Schulze CJ, Hervas-Malo M, Wang P, Ross DB, Zibdawi M, Bagshaw SM: Difference between pre-operative and cardiopulmonary bypass mean arterial pressure is independently associated with early cardiac surgeryassociated acute kidney injury. J Cardiothorac Surg 2010, 5:71.

33. Thurau K, Boylan JW: Acute renal success. The unexpected logic of oliguria in acute renal failure. Am J Med 1976, 61:308-315.

34. Rosenberger C, Rosen S, Heyman SN: Renal parenchymal oxygenation and hypoxia adaptation in acute kidney injury. Clin Exp Pharmacol Physiol 2006, 33:980-988

35. Molitoris BA, Falk SA, Dahl RH: Ischemia-induced loss of epithelial polarity. Role of the tight junction. J Clin Invest 1989, 84:1334-1339.

36. Molitoris $\mathrm{BA}: \mathrm{Na}(+)-\mathrm{K}(+)$-ATPase that redistributes to apical membrane during ATP depletion remains functional. Am J Physiol 1993, 265:F693-697.

37. Laycock SK, Vogel T, Forfia PR, Tuzman J, Xu X, Ochoa M, Thompson Cl, Nasjetti A, Hintze TH: Role of nitric oxide in the control of renal oxygen consumption and the regulation of chemical work in the kidney. Circ Res 1998, 82:1263-1271.

38. Cleeter MW, Cooper JM, Darley-Usmar VM, Moncada S, Schapira AH: Reversible inhibition of cytochrome c oxidase, the terminal enzyme of the mitochondrial respiratory chain, by nitric oxide. Implications for neurodegenerative diseases. FEBS Lett 1994, 345:50-54.

39. Valsson F, Ricksten SE, Hedner T, Lundin S: Effects of atrial natriuretic peptide on acute renal impairment in patients with heart failure after cardiac surgery. Intensive Care Med 1996, 22:230-236.

40. Sward K, Valsson F, Odencrants P, Samuelsson O, Ricksten SE: Recombinant human atrial natriuretic peptide in ischemic acute renal failure: a randomized placebo-controlled trial. Crit Care Med 2004, 32:1310-1315.

41. Burke TJ, Cronin RE, Duchin KL, Peterson LN, Schrier RW: Ischemia and tubule obstruction during acute renal failure in dogs: mannitol in protection. Am J Physiol 1980, 238:F305-F314.

42. Valdes ME, Landau SE, Shah DM, Newell JC, Scovill WA, Stratton H, Rhodes GR, Powers SR Jr: Increased glomerular filtration rate following mannitol administration in man. J Surg Res 1979, 26:473-477.
43. Molitoris BA, Sandoval R, Sutton TA: Endothelial injury and dysfunction in ischemic acute renal failure. Crit Care Med 2002, 30:S235-S240

44. Bragadottir G, Redfors B, Ricksten SE: Mannitol increases renal blood flow and maintains filtration fraction and oxygenation in postoperative acute kidney injury - a prospective interventional study. Crit Care 2012, 16:R159.

45. Kristof AS, Magder S: Low systemic vascular resistance in patients undergoing cardiopulmonary bypass. Crit Care Med 1999, 27:1121-1127.

46. Dellinger RP, Levy MM, Carlet JM, Bion J, Parker MM, Jaeschke R, Reinhart K, Angus DC, Brun-Buisson C, Beale R, Calandra T, Dhainaut JF, Gerlach H, Harvey M, Marini JJ, Marshall J, Ranieri M, Ramsay G, Sevransky J, Thompson BT, Townsend S, Vender JS, Zimmerman JL, Vincent JL: Surviving sepsis campaign: international guidelines for management of severe sepsis and septic shock. Intensive Care Med 2008, 34:17-60.

47. Redfors B, Bragadottir G, Sellgren J, Sward K, Ricksten SE: Effects of norepinephrine on renal perfusion, filtration and oxygenation in vasodilatory shock and acute kidney injury. Intensive Care Med 2011, 37:60-67.

48. Landry DW, Oliver JA: The pathogenesis of vasodilatory shock. N Engl J Med 2001, 345:588-595.

49. Landry DW, Levin HR, Gallant EM, Seo S, D'Alessandro D, Oz MC, Oliver JA: Vasopressin pressor hypersensitivity in vasodilatory septic shock. Crit Care Med 1997, 25:1279-1282.

50. Patel BM, Chittock DR, Russell JA, Walley KR: Beneficial effects of short-term vasopressin infusion during severe septic shock. Anesthesiology 2002, 96:576-582.

51. ter Wee PM, Smit AJ, Rosman JB, Sluiter WJ, Donker AJ: Effect of intravenous infusion of low-dose dopamine on renal function in normal individuals and in patients with renal disease. Am J Nephrol 1986, 6:42-46.

52. Schoors DF, Dupont AG: Further studies on the mechanism of the natriuretic response to low-dose dopamine in man: effect on lithium clearance and nephrogenic cAMP formation. Eur J Clin Invest 1990, 20:385-391.

53. Olsen NV, Lund J, Jensen PF, Espersen K, Kanstrup IL, Plum I, Leyssac PP: Dopamine, dobutamine, and dopexamine. A comparison of renal effects in unanesthetized human volunteers. Anesthesiology 1993, 79:685-594

54. Olsen NV, Hansen JM, Kanstrup IL, Richalet JP, Leyssac PP: Renal hemodynamics, tubular function, and response to low-dose dopamine during acute hypoxia in humans. J Appl Physiol 1993, 74:2166-2173.

55. Olsen NV, Lang-Jensen T, Hansen JM, Plum I, Thomsen JK, Strangaard S, Leyssac PP: Effects of acute beta-adrenoceptor blockade with metoprolol on the renal response to dopamine in normal humans. $\mathrm{Br} J \mathrm{Clin}$ Pharmacol 1994, 37:347-353

56. Richer M, Robert S, Lebel M: Renal hemodynamics during norepinephrine and low-dose dopamine infusions in man. Crit Care Med 1996, 24:1150-1156

57. Mc Donald RH, Goldberg LI, McNay JL, Tuttle EP: Effect of dopamine in man: Augmentation of sodium excretion, glomerular filtration rate and renal plasma flow. J Clin Invest 1964, 43:1116-1124.

58. Rosenblum R, Tai AR, Lawson D: Dopamine in man: cardiorenal hemodynamics in normotensive patients with heart disease. J Pharmacol Exp Ther 1972, 183:256-263.

59. Schwartz LB, Bissell MG, Murphy M, Gewertz BL: Renal effects of dopamine in vascular surgical patients. J Vasc Surg 1988, 8:367-374.

60. Graves TA, Cioffi WG, Vaughan GM, Pratt L, Heironimus JD, McManus WF, Pruitt BA Jr: The renal effects of low-dose dopamine in thermally injured patients. J Trauma 1993, 35:97-102.

61. Ungar A, Fumagalli S, Marini M, Di Serio C, Taranti F, Boncinelli G, Valoti P, La Cava G, Oliani C, Masotti G, Marchionni N: Renal, but not systemic, hemodynamic effects of dopamine are influenced by the severity of congestive heart failure. Crit Care Med 2004, 32:1125-1129.

doi:10.1186/cc12530

Cite this article as: Ricksten SE, et al.: Renal oxygenation in clinical acute kidney injury. Critical Care 2013, 17:221. 